\title{
Influence of indications on perinatal outcomes after radio frequency ablation in complicated monochorionic pregnancies: a retrospective cohort study
}

Hongmei Wang ${ }^{1}$, Qian Zhou' ${ }^{1}$, Xietong Wang ${ }^{1,2,3}$, Jia Song ${ }^{4}$, Pengzheng Chen ${ }^{1}$, Yanyun Wang ${ }^{1}$, Lei Li ${ }^{1}$ and Hongyan $\mathrm{Li}^{1^{*}}$ (D)

\begin{abstract}
Background: Radiofrequency ablation (RFA) is recommended to prevent potential neurological injury or intrauterine foetal death (IUFD) of the co-twin(s) in complicated monochorionic (MC) pregnancies. However, the impacts of various indications on the pregnancy outcome following RFA remain unclear. This study aimed to determine how the indications influence the perinatal outcomes in complicated $M C$ pregnancies undergoing radiofrequency ablation.

Methods: This was a retrospective cohort study performed in a single centre. All consecutive MC pregnancies treated with RFA between July 2011 and July 2019 were included. The adverse perinatal outcomes and the survival rate were analysed based on various indications. The continuous variables with and without normal distribution were compared between the groups using Student's t-test and Mann-Whitney $U$ test, respectively, and for categorical variables, Chi-square and Fisher's exact tests were used. $P<0.05$ indicated a significant difference.

Results: We performed 272 RFA procedures in 268 complicated MC pregnancies, including 60 selective intrauterine growth restriction (sIUGR), 64 twin-twin transfusion syndrome (TTS), 12 twin reversed arterial perfusion sequence (TRAPs), 66 foetal anomaly and 66 elective foetal reduction (EFR) cases. The overall survival rate of the co-twin was 201/272 (73.9\%). The overall technical successful rate was determined at 201/263 (76.7\%). The IUFD rate in the cotwin was 20/272 (7.4\%). The TTS group had recorded the lowest survival rate $(37 / 64,57.8 \%)$, and the survival rate was significantly correlated with Quintero stages $(P=0.029)$. Moreover, the sIUGR III subgroup had a lower survival rate compared with sIUGR II (55.6\%, versus $84.3 \%)$. The subgroup of foetal anomaly of gastroschisis or exomphalos had the highest IUFD rate (4/10,40\%), followed by sIUGR III (2/9,22.2\%) and dichorionic triamniotic (DCTA) subgroup $(8 / 46,17.9 \%)$. In EFR group, eight IUFD cases were all coming from the DCTA subgroup and received RFA before 17 weeks.

* Correspondence: hoy0529@126.com

1 Department of Obstetrics, Shandong Provincial Hospital Affiliated to

Shandong First Medical University, Jinan, Shandong, China

Full list of author information is available at the end of the article

C C The Author(s). 2021 Open Access This article is licensed under a Creative Commons Attribution 4.0 International License, which permits use, sharing, adaptation, distribution and reproduction in any medium or format, as long as you give appropriate credit to the original author(s) and the source, provide a link to the Creative Commons licence, and indicate if changes were made. The images or other third party material in this article are included in the article's Creative Commons licence, unless indicated otherwise in a credit line to the material. If material is not included in the article's Creative Commons licence and your intended use is not permitted by statutory regulation or exceeds the permitted use, you will need to obtain permission directly from the copyright holder. To view a copy of this licence, visit http://creativecommons.org/licenses/by/4.0/. The Creative Commons Public Domain Dedication waiver (http://creativecommons.org/publicdomain/zero/1.0/) applies to the data made available in this article, unless otherwise stated in a credit line to the data. 
(Continued from previous page)

Conclusions: The perinatal outcome of RFA was correlated with the indications, with the lowest survival rate in TIS IV and the highest IUFD incidence in abdominal wall defect followed by sIUGR III. Elective RFA after 17 weeks may prevent IUFD in DCTA pregnancies.

Keywords: Complicated monochorionic pregnancy, Intrauterine foetal death, Radiofrequency ablation, Selective foetal reduction, Selective intrauterine growth restriction, Twin-twin transfusion syndrome, Twin reversed arterial perfusion sequence, Umbilical cord occlusion

\section{Background}

Around one-third of the monochorionic (MC) multiple pregnancies suffer from specific complications such as twin-twin transfusion syndrome (TTTS), selective intrauterine growth restriction (sIUGR), twin reversed arterial perfusion sequence (TRAPs) and twin anaemia polycythaemia sequence (TAPS) [1, 2]. For complicated MC pregnancies, selective foetal reduction by umbilical cord occlusion (UCO) is recommended to prevent potential neurological injury or intrauterine foetal death (IUFD) of the remaining foetus [3-5].

UCO techniques include laser cord coagulation [6], cord ligation [7], bipolar cord coagulation [4, 7], radiofrequency ablation (RFA) [8-10], microwave ablation [11] and high-intensity focused ultrasound [12]. The optimal method of UCO remains to be determined. RFA, using a 17 -gauge needle to ablate tissues within $2 \mathrm{~cm}$ diameter, is relatively simple and effective, obtaining a lower incidence of preterm premature rupture of membranes (PPROM) and preterm delivery $[5,8,13]$. Other advantages that make RFA the preferred technique involve situations where there is difficulty in terms of access to other surgical treatments, including oligohydramnios of the target twin, proximity of twin cord insertion sites, anterior placenta or earlier gestational age [14].

The primary indications for RFA are TRAPs and other lethal foetal anomalies [14]. After RFA, the overall survival rate of the co-twin in TRAPs is determined to be at $75.0-92 \%$ [8-10, 15-19], but it varies in other anomalies, ranging $33-92.3 \%[8,13,15]$. RFA is also recommended for sIUGR in which laser may not be a desirable choice for large vessel anastomosis [5, 20, 21]. Although foetoscopic laser photocoagulation (FLP) is currently the standard treatment for TTTS stages II-IV [22-24], selective foetal reduction is still required, because this technique is still not available in many areas, or the surgeons are not experienced, especially in patients with an anterior placenta. At times, parents prefer to undergo RFA owing to concerns regarding the foetal outcome. Maternal reasons included history of caesarean section or cervical incompetence, and increased maternal age $[25,26]$.

However, the effects of these indications on the pregnancy outcome following RFA remain undefined.
Therefore, by examining a large cohort of complicated MC pregnancies undergoing RFA, we determined how the various indications influenced the perinatal outcome after RFA treatment.

\section{Methods}

\section{Study population}

This retrospective cohort study enrolled all cases of consecutive MC pregnancies treated with RFA in a single tertiary centre between July 2011 and July 2019. The indications for RFA were as follows: sIUGR II and III [27]; TTTS stages III-IV [28]; MC twins discordant for foetal anomaly (MTDFA); TRAPs (abdominal circumference of the acardiac twin larger than that of the pump twin) and elective foetal reduction (EFR) for multiple pregnancies containing MC components. We also included those patients with TTTS II who chose foetal reduction of an $\mathrm{MC}$ co-twin for maternal reasons. Conversely, RFA contraindications were as follows: $<2.5 \mathrm{~cm}$ cervical length, uterine contraction, vaginal bleeding or severe maternal complications. The ethics committee of Shandong Provincial Hospital affiliated to Shandong First Medical University has approved this study, and the registry number is 2011-023.

\section{Description of procedure}

Patients underwent a comprehensive ultrasound examination to determine the chorionicity status, placental position, malformations, amniotic fluid's deepest vertical pocket, cervical length, umbilical artery blood flow and the middle cerebral artery peak systolic velocity (MCAPSV). Patients and their families received detailed counselling regarding the risks of RFA, including cotwin demise, miscarriage, preterm labour and neurological or thermal injury to the surviving foetus. Written consent forms were signed by patients.

All RFA procedures were performed under local anaesthesia, and either supine or lateral position was used depending on the convenience of access to the targeted vessel. Under ultrasound guidance, a 17-gauge Sarburst radiofrequency needle (RITA Medical Systems, Fremont, CA, USA) was inserted to get near to the abdominal segment of the foetal umbilical vessel, trying to avoid the placenta and amniotic sac of the retained foetus(es). The 
accuracy of the ablation area is essential for the success of the RFA procedure. If the umbilical vessels could not be surrounded by the tines, the position of the needle was adjusted.

Three electrodes were ejected to surround the cord vessels after the tine position was confirmed. Radiofrequency energy was applied for $3 \mathrm{~min}$ at 150 watts to generate the target temperature of $100{ }^{\circ} \mathrm{C}-110{ }^{\circ} \mathrm{C}$. If the three electrode tines did not exhibit a synchronous temperature increase (difference: $>30{ }^{\circ} \mathrm{C}$ ), they were retracted, and the position was then adjusted. During and after each ablation cycle, the blood flow in the targeted vessels was observed using the colour Doppler until the blood flow signal was completely absent. The heart rate of the targeted foetus was then monitored until it decreased to $<60 \mathrm{bpm}$. However, the disappearance of the blood flow signal in the umbilical vessels does not always indicate a complete blockage; it may be merely too weak to be detected after a reflective decrease of the heart rate and output or spasm of the vessel. If the heartbeat stopped earlier or the decrease of the heartbeat was slower than expected, another ablation cycle was planned.

An ultrasound examination was performed $24 \mathrm{~h}$ after the procedure to evaluate the surviving foetus, the systolic/diastolic pressure of the umbilical artery and MCA-PSV and cervical length. Thereafter, further ultrasound scan was performed every 2 weeks. MRI was also performed at 24-28 weeks to detect any foetal brain damage. Subsequently, the patients were allowed to consult and deliver in local hospitals.

\section{Data collection}

The following data of all the consecutive patients who underwent RFA were retrieved from our database: maternal age, indications for foetal reduction, gestational age at procedure, postprocedural complications, subsequent ultrasound scan and foetal brain MRI results. Furthermore, the following perinatal outcomes were also recorded: IUFD of the co-twin, PPROM within 2 weeks after the RFA, termination of pregnancy (TOP) and preterm delivery $<28$ weeks, gestational age at delivery and birth weight and perinatal mortality. In cases delivered elsewhere, we gathered the delivery and neonatal information, and a neonatologist evaluated the condition of the newborns according to the Gessel Developmental Schedule [29], both via a telephone interview with the parents.

\section{Statistical analysis}

Patients were divided into five groups based on their conditions, namely, sIUGR, TTTS, TRAPs, MTFDA and EFR. They were further split into subgroups according to the type of sIUGR, Quintero stage of TTTS, position of foetal anomaly and the chorionicity of EFR. The incidence rate was calculated per procedure because some patients had undergone two procedures. The survival rate was calculated when the co-twin(s) were delivered after 28 weeks and the newborn was alive at 28 days. Technical successful rate was calculated to exclude those TOP cases after RFA because of foetal anomaly or other reasons and those who gave up further treatment on the premature newborns. Take-baby-home rate per patient was also calculated because most triplet pregnancies receiving RFA were successful despite the co-twin demise.

Data were analysed using the SPSS version 25.0 software (IBM SPSS Statistics). Continuous variables are presented as mean and standard deviation, whereas categorical variables are expressed as absolute numbers and percentages. The continuous variables with and without normal distribution were compared between the groups by Student's $t$-test and Mann-Whitney $U$ test, respectively; for categorical variables, we used the chi-square and Fisher's exact tests. Differences were considered significant when $P<0.05$.

\section{Results}

Table 1 presents the characteristics and the overall pregnancy outcomes for the total population and the five groups. During the study period, 272 RFA procedures were performed in 268 patients; two procedures were performed in one patient including 2 TRAPs $[1$ monochorionic tramniotic (MCTA) and 1 monochorionic quadramniotic (MCQA)], 1 MCQA with foetal anomaly, 1 DCQA with EFR. We found 60 sIUGR, 64 TTTS, 12 TRAPs, 66 foetal anomaly and 70 EFR cases. The median gestational age at procedure in the total population was determined to be at $20.05 \pm 3.41$ weeks, and that in the EFR group $(16.73 \pm 1.31$ weeks) was significantly the earliest among the five groups $(P<0.001)$. The EFR group achieved the best pregnancy outcome followed by the sIUGR group, with the same co-twin survival rate (80.0\%) and a higher take-baby-home rate in the EFR group (85.1\%). The overall survival rate of the co-twin was determined to be $201 / 272$ (73.9\%). The median gestational age at delivery was $36.3 \pm 2.9$ weeks, with an average birth weight of $2662.5 \pm 707.8 \mathrm{~g}$. After the exclusion of those who opted for TOP $(n=7)$ and who gave up on postnatal treatment $(n=2)$, the overall technical successful rate was 201/263 (76.4\%).

IUFD of the co-twin occurred in 20/272 (7.4\%) procedures of the total population and $17 / 20(85.0 \%)$ procedures within 2 days after RFA. The incidence of premature rupture of membranes (PROM) within 2 weeks after RFA was at 14/272 (5.1\%). Elective TOP was preferred by parents for dysplasia in the co-twin including severe oedema $(n=3)$ and tricuspid insufficiency $(n=2)$ in the TTTS group and cleft palate in the 
Table 1 Characteristics and perinatal outcomes in complicated multiple pregnancies undergoing RFA

\begin{tabular}{|c|c|c|c|c|c|c|c|}
\hline Characteristic & sIUGR $(n=60)$ & TTTS $(n=64)$ & TRAPs $(n=12)$ & $\begin{array}{l}\text { Foetal anomaly } \\
(n=66)\end{array}$ & $\operatorname{EFR}(n=70)$ & $\begin{array}{l}\text { Sum } \\
(n=272)\end{array}$ & $P$ \\
\hline Age pregnancy & $31.17 \pm 4.82$ & $30.83 \pm 4.64$ & $30.33 \pm 5.68$ & $30.85 \pm 4.86$ & $31.10 \pm 4.57$ & $30.96 \pm 4.73 y$ & 0.982 \\
\hline GA at procedure & $22.04 \pm 2.77$ & $21.17 \pm 2.77$ & $21.42 \pm 4.22$ & $20.45 \pm 3.51$ & $16.73 \pm 1.31$ & $20.05 \pm 3.41 w$ & $<0.001$ \\
\hline IUFD & $2(3.3 \%)$ & $3(4.7 \%)$ & 0 & $7(10.6 \%)$ & $8(11.4 \%)$ & $20(7.4 \%)$ & 0.217 \\
\hline PROM within $2 \mathrm{w}$ & $5(8.3 \%)$ & $5(7.8 \%)$ & $1(8.3 \%)$ & $2(3.0 \%)$ & $1(1.4 \%)$ & $14(5.1 \%)$ & 0.286 \\
\hline TOP & 0 & $5(7.8 \%)$ & $1(8.3 \%)$ & $1(1.5 \%)$ & 0 & $7(2.6 \%)$ & 0.015 \\
\hline $\begin{array}{l}\text { Miscarriage } \\
(>2 w \text { after RFA) }\end{array}$ & $3(5.0 \%)$ & $11(17.2 \%)$ & $1(8.3 \%)$ & $5(7.6 \%)$ & $5(7.1 \%)$ & $25(9.2 \%)$ & 0.151 \\
\hline Delivery at $28-31^{+6} \mathrm{~W}$ & $4(6.7 \%)$ & $4(6.3 \%)$ & 0 & $2(3.0 \%)$ & 0 & $10(3.7 \%)$ & 0.205 \\
\hline Delivery at $32-33^{+6} \mathrm{w}$ & $7(11.7 \%)$ & 12(18.8\%) & $4(33.3 \%)$ & $12(18.2 \%)$ & 25(35.7\%) & $60(22.1 \%)$ & 0.010 \\
\hline Delivery at 37w- & $37(61.7 \%)$ & $21(32.8 \%)$ & $5(41.7 \%)$ & $37(56.1 \%)$ & $31(44.3 \%)$ & $131(48.2 \%)$ & 0.013 \\
\hline GA at delivery(w) & $36.58 \pm 3.28$ & $35.35 \pm 3.72$ & $36.46 \pm 2.60$ & $36.93 \pm 2.61$ & $36.29 \pm 1.92$ & $36.34 \pm 2.90 w$ & 0.265 \\
\hline Birth weight & $2983.80 \pm 797.30$ & $2459.25 \pm 777.58$ & $2731.11 \pm 599.45$ & $2768.24 \pm 669.14$ & $2413.39 \pm 463.36$ & $2662.48 \pm 707.80$ & $<0.001$ \\
\hline Technical success & 48(80.0\%) & $37(64.9 \%)$ & $9(81.8 \%)$ & $51(78.5 \%)$ & $56(80.0 \%)$ & $201(76.4 \%)$ & 0.245 \\
\hline Neonatal death & $2(3.3 \%)$ & $3(4.7 \%) \#$ & 0 & 0 & 0 & $5(1.8 \%) \#$ & 0.341 \\
\hline Survival rate of co-twin & 48(80.0\%) & $37(57.8 \%)$ & $9(75.0 \%)$ & $51(77.3 \%)$ & $56(80.0 \%)$ & $201(73.9 \%)$ & 0.022 \\
\hline Take-baby-home rate & 48(80.0\%) & $37(57.8 \%)$ & $9(75.0 \%)$ & $51(77.3 \%)$ & $57 / 67(85.1 \%)$ & 202/268(75.3\%) & 0.020 \\
\hline
\end{tabular}

Data are presented as mean $\pm S D, n(\%)$.\#Treatment was given up by the parents for worrying about the potential longterm developmental retardation

Table 2 Perinatal outcomes after RFA in complicated monochorionic pregnancies stratified by indications

\begin{tabular}{|c|c|c|c|c|c|c|c|}
\hline & Subgroups & IUFD & $\begin{array}{l}2 \mathrm{~W} \\
\text { PROM }\end{array}$ & $\begin{array}{l}\text { Miscarriage } \\
\left(>2 \mathrm{w} \text { after } \mathrm{RFA}^{*}\right)\end{array}$ & TOP & $\begin{array}{l}\text { Neonatal } \\
\text { death }\end{array}$ & $\begin{array}{l}\text { Technical } \\
\text { success }\end{array}$ \\
\hline \multirow[t]{3}{*}{ sIUGR $(n=60)$} & $\|(n=51)$ & 0 & $4(7.8 \%)$ & $3(5.9 \%)$ & 0 & $1(2.0 \%)$ & $43 / 51(84.3 \%)$ \\
\hline & $\| I I(n=9)$ & $2(22.2 \%)$ & $1(11.1 \%)$ & 0 & 0 & $1(11.1 \%)$ & $5 / 9(55.6 \%)$ \\
\hline & $P$ & 0.020 & 0.570 & 1.000 & - & 0.280 & 0.069 \\
\hline \multirow[t]{4}{*}{ TTS $(n=64)$} & $\|(n=11)$ & 0 & 0 & 0 & 0 & 0 & $10(100.0 \%)$ \\
\hline & III $(n=39)$ & $2(5.1 \%)$ & $5(12.8 \%)$ & $5(12.8 \%)$ & $2(5.1 \%)$ & $1(2.6 \%)$ & $23(63.9 \%)$ \\
\hline & $\mathrm{IV}(n=14)$ & $1(7.1 \%)$ & 0 & $6(42.9 \%)$ & $3(21.4 \%)$ & 0 & $4(36.4 \%)$ \\
\hline & $P$ & 0.688 & 0.176 & 0.010 & 0.085 & 0.722 & 0.009 \\
\hline TRAPS $(n=12)$ & $\operatorname{TRAP}(n=12)$ & 0 & $1(8.3 \%)$ & $1(8.3 \%)$ & $1(8.3 \%)$ & 0 & $9(81.8 \%)$ \\
\hline \multirow{6}{*}{$\begin{array}{l}\text { Discordant for foetal anomaly } \\
(n=66)\end{array}$} & Central neural system $(n=20)$ & 0 & $1(5.0 \%)$ & $2(10.0 \%)$ & $1(5.0 \%)$ & 0 & $16(84.2 \%)$ \\
\hline & Heart $(n=10)$ & $2(20 \%)$ & 0 & 0 & 0 & 0 & $8(80.0 \%)$ \\
\hline & Edema $(n=13)$ & 0 & $1(7.7 \%)$ & $2(15.4 \%)$ & 0 & 0 & $10(76.9 \%)$ \\
\hline & Gastrochisis, Exompholos $(n=10)$ & $4(40 \%)$ & 0 & 0 & 0 & 0 & $6(60.0 \%)$ \\
\hline & Other $(n=13)$ & $1(7.7 \%)$ & 0 & $1(7.7 \%)$ & 0 & 0 & $11(84.6 \%)$ \\
\hline & $P$ & 0.007 & 0.689 & 0.568 & 0.674 & - & 0.607 \\
\hline \multirow[t]{4}{*}{$\operatorname{EFR}(n=70)$} & $\mathrm{DCTA}(n=46)$ & $8(17.4 \%)$ & 0 & $3(6.5 \%)$ & 0 & 0 & $35(76.1 \%)$ \\
\hline & $\operatorname{MCTA}(n=17)$ & 0 & $1(5.9 \%)$ & $2(11.8 \%)$ & 0 & 0 & $14(82.4 \%)$ \\
\hline & Other $(n=7)$ & 0 & 0 & 0 & 0 & 0 & $7(100.0 \%)$ \\
\hline & $P$ & 0.095 & 0.181 & 0.513 & - & - & 0.293 \\
\hline Sum $(n=272)$ & $P$ & $<0.001$ & 0.470 & 0.015 & 0.009 & 0.586 & 0.020 \\
\hline
\end{tabular}

Data are presented as mean $\pm \mathrm{SD}, \mathrm{n}(\%)$ 
MTDFA group $(n=1)$ and of maternal complication $(n=1)$ in the TRAPs group. The highest IUFD rate was found in the EFR group (8/70,11.4\%), followed by the MTDFA group (7/66, 10.6\%), whereas the lowest IUFD rate was found in the TRAPs group $(0 / 12,0 \%)$, followed by the sIUGR group $(2 / 60,3.33 \%)$. Meanwhile, the lowest survival rate of $37 / 64$ (57.8\%) was recorded in the TTTS group, considering the three IUFD (4.7\%) and five PROM (7.8\%) cases within 2 weeks after the procedure, five TOP cases for tricuspid insufficiency and severe hydrops foetalis and the highest miscarriage rate.

The pregnancy outcomes stratified by the types of sIUGR, Quintero stages of TTTS, position of foetal anomaly in the MTDFA group and chorionicity of EFR are presented in Table 2. The survival rate of the subgroup of TTTS stages II, III and IV was 100\%, 63.9\% and $36.4 \%$, respectively, and is significantly correlated with Quintero stages $(P=0.029)$. The technical successful rate in sIUGR III $(5 / 9,55.6 \%)$ was lower than that in sIUGR II (43/51, 84.3\%), but the difference was not significant, probably owing to the small sample size of the sIUGR III subgroup $(P=0.069)$. The highest IUFD rate $(4 / 10,40 \%)$ was found in the subgroup of foetal anomaly in the abdominal wall (gastroschisis or exomphalos), followed by the subgroups of sIUGR III $(2 / 9,22.2 \%)$ and dichorionic triamniotic (DCTA) for EFR (8/46, 17.4\%).

The EFR group involved 46 DCTA, 17 MCTA, 1 DCQA (2 procedures in one patient), and 5 MCDA twin pregnancies choosing foetal reduction. With no IUFD after RFA, the pregnancy outcome in the MCTA subgroup was found to be slightly better than that in the DCTA subgroup $(81.3 \%$ vs. $76.1 \%, P=0.607)$. The eight IUFD cases were all from the DCTA subgroup and received RFA before 17 weeks; for those who received RFA after 17 weeks $(n=19)$, they all ended with desirable outcomes regardless of the chorionicity (Fig. 1).
During the RFA procedure, 25 patients presented with supine hypotension, which was relieved after changing the body position and providing oxygen inhalation. No severe maternal complication such as deep vein thrombosis or burn in the skin was found. Only one patient exhibited iatrogenic septostomy 5 days after RFA, with no adverse outcome. Furthermore, one patient experienced chorioamnionitis 9 days after RFA, followed by TOP.

Table 3 presents other postprocedural pregnancy complications. TTTS was found to occur in two patients with MCTA; one underwent abortion at $25^{+6}$ weeks after serial amnioreduction, whereas the other one delivered at $32^{+4}$ weeks. Placenta abruption, preeclampsia and acute pancreatitis were also found to occur in late pregnancy, but with timely caesarean section, the outcome was successful.

None of the surviving co-twins showed increased MCA-PSV at follow-up with ultrasound, or abnormal foetal brain MR, except for mild ventriculomegaly in one pregnancy $(1.2 \mathrm{~cm})$. Treatment of the two preterm newborns delivered at $27^{+2}$ weeks and $28^{+2}$ weeks was stopped by their parents as they were worried about the potential neurodevelopmental retardation. One delivered at $30^{+5}$ weeks with severe infection, and two preterm newborns delivered at $28^{+}$weeks died despite receiving active treatment in local hospitals. Nonetheless, 6/10 neonates delivered between 28 and 32 weeks were doing well after NICU admission. In the follow-up interview, all children met the main criteria based on their age, and none of the parents complained about any developmental problems of their children.

\section{Discussion}

This study investigated the perinatal outcome of 268 MC pregnancies undergoing 272 RFA procedures, and

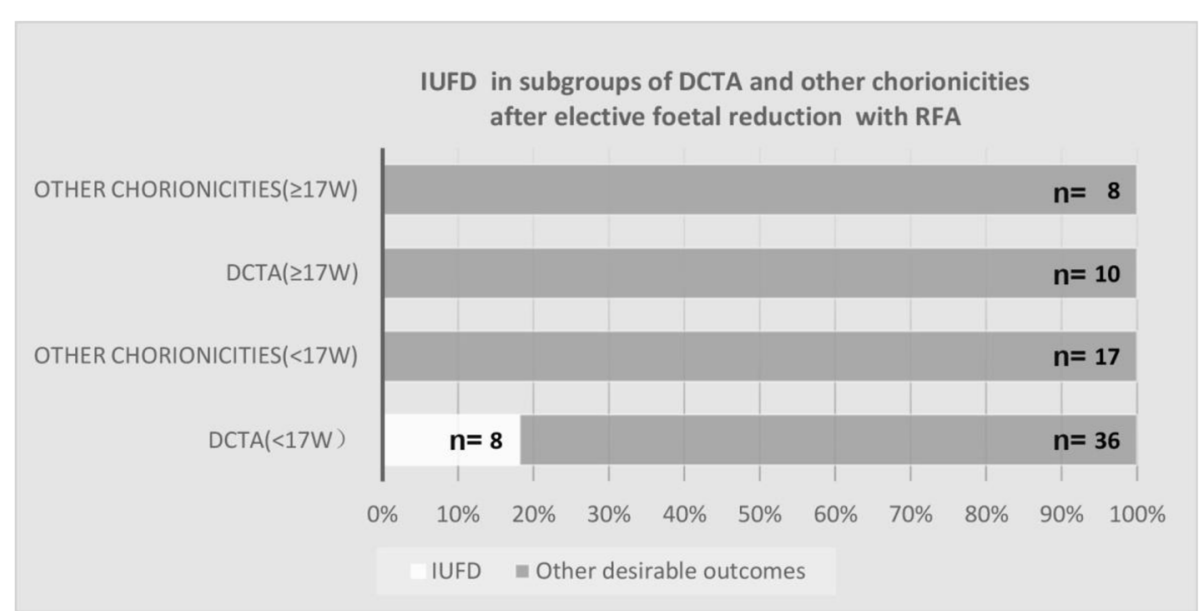

Fig. 1 IUFD after elective foetal reduction with RFA in subgroup of DCTA and other chorionities 
Table 3 Other perinatal complications may affect the pregnancy outcome after RFA

\begin{tabular}{llllll}
\hline Complications & Chorionicity & Indication for RFA & GA at delivery (week) & Prolonged GA (week) & Pregnancy outcome \\
\hline Pre-eclampsia & DCTA & EFR & $36^{+4}$ & $20^{+2}$ & $3070 \mathrm{~g} / 2990 \mathrm{~g}$ \\
Acute pancreatitis & DCTA & EFR & $29^{+4}$ & $13^{+5}$ & $1400 \mathrm{~g} / 1300 \mathrm{~g}$ \\
Placental abruption & MCDA & SIUGRII & $34^{+3}$ & $10^{+3}$ & $2300 \mathrm{~g}$ \\
Placental abruption & MCDA & SIUGRIII & $32^{+4}$ & $6^{+6}$ & $3000 \mathrm{~g}$ \\
TTTS & MCTA & EFR & $25^{+6}$ & $6^{+3}$ & Abortion after amnioreduction \\
TTTS & MCTA & EFR & $32^{+4}$ & $13^{+2}$ & $1760 \mathrm{~g} / 2020 \mathrm{~g}$ \\
\hline
\end{tabular}

the overall survival rate was $73.9 \%$ in the co-twins. Postprocedural complications of RFA include thermal injuries [5, 8], IUFD and brain damage to the retained co-twin $[8,21,30]$ and preterm birth $[16,31]$. However, the effects of various indications on the adverse perinatal outcomes after RFA are still poorly understood. In this study, considering the large cohort size, we could analyze the pregnancy outcomes stratified by the indications of TTTS, sIUGR, TRAPs, discordant anomaly and EFR, and further investigate how the types of sIUGR, Quintero stages of TTTS, the position of foetal anomaly and the chorionicity of EFR contributed to the perinatal outcome after RFA.

The perinatal outcome was found to be significantly different with respect to various indications. Regarding the survival rate, the lowest was recorded in the TTTS group, whereas the highest was in the EFR and sIUGR groups, conforming to previous studies $[8,13,15,19$, 25]. Kumar [8] and Yinon [19] reported a survival rate of $38 / 38$ and $17 / 19$ in the sIUGR group separately and that sIUGR as an indication for RFA had a more favourable perinatal outcome than other indications. In the current study, the poor perinatal outcome in the TTTS group and the unexpectedly lower survival rate in the MTDFA group could be explained by further subgroup analysis.

The perinatal outcomes were found to be significantly correlated with the Quintero stages of TTTS, which was worst in TTTS IV, having higher incidences of polyhydramnios and miscarriage, and selective termination for severe tricuspid insufficiency or oedema in the retained foetus. The sIUGR II subgroup was able to obtain a better survival rate than the sIUGR III subgroup, probably contributed by the higher incidence of IUFD in the subgroup sIUGR III, which involves larger artery-artery anastomosis $[1,25]$, allowing more blood exchange during ablation.

Additionally, two subgroups had high IUFD rates. As for the high rate of $40 \%$ in the subgroup of foetal anomaly in the anterior abdominal wall (gastroschisis or exomphalos), with the proximity of the target vessel and the heart of the targeted twin, we speculate that the disappearance of the cord blood flow during RFA might be the consequence of the damage to the heart caused by ablation energy rather than a complete blockage of the blood flow, and subsequent exsanguination resulted in the co-twin demise. This finding provided an evidence to consider other UCO techniques in similar situations. Furthermore, an unexpected higher rate of $8 / 46$ was found in the DCTA subgroup, with all IUFD cases occurred in those performed before 17 weeks, wherein technical difficulty was worsened by the small size of the targeted foetus. Meanwhile, IUFD did not occur in the MCTA subgroup with the same gestational age, probably because of the flexible option in any of the three foetuses, making the process technically simpler than in DCTA cases wherein only two of the three foetuses could be targeted. Technical difficulty and subsequent IUFD in the DCTA subgroup could be partially avoided by performing the procedure after 17 weeks.

The accurate mechanism of the co-twin demise remains unclear. Subsequent exsanguination caused by an incomplete blockage in the targeted vessel after ablation might be a reason [4]. In this study, no IUFD in the TRAPs group and the sIUGR II subgroup could be an indirect evidence for this presumption. The blood flow in the targeted vessels, completely from the donor twin or mainly from the retained larger co-twin, was not prone to be affected by the output from the reduced twin [8]. Blood flow disappearance indicated a complete blockage; hence, postprocedural exsanguination was avoided.

The incidence of brain damage and neurodevelopmental impairment in the reserved co-twin was reported to be $2 / 103$ in a systematic review [30] and 5/74 in an observational cohort study after selective foeticide in $\mathrm{MC}$ pregnancies [32]. In this cohort, no neurodevelopmental retardation was found, except for mild ventriculomegaly in one pregnancy, and all children were observed to be doing well. The reason could be that delivery before 28 weeks was considered as an abortion in local hospitals and most of those newborns delivered before 28 weeks died without active treatment. Preterm birth as a consequence of PROM was considered as one of the main risk factors for adverse perinatal outcomes after foetal intervention $[16,31]$.

The limitation of this study lies in its retrospective nature. The initial case selection such as selective 
avoidance of sIUGR III and TTTS IV, leading to the small sample size in certain subgroups, may result in statistical bias. Moreover, some surgical details, such as placental penetration, entry of a twin sac and whether the reduced twin was the presenting twin, were missed. Another shortcoming is owing to the distance from the patients' home to our hospital, most patients were followed up and delivered at local hospitals where viable preterm newborns had to be given up and most of the neurodevelopmental follow-up was merely assessed via telephone interview. Long-term follow-up with a standard cognitive and developmental scale is necessary.

\section{Conclusions}

Compared to previous publications, this is the largest cohort study regarding the perinatal outcomes of RFA stratified by all possible indications. Furthermore, all of the procedures were conducted by one experienced operator and the same sonographer, thereby maximally decreasing the influence of the technique and measurement bias. In conclusion, the pregnancy outcome after RFA was found to be correlated to the indication, with the lowest survival rate in TTTS IV cases and the highest IUFD incidence in foetal anomaly cases affecting the anterior abdominal wall, followed by the sIUGR III cases. Selective RFA after 17 weeks may help prevent IUFD in DCTA pregnancies.

\section{Abbreviations}

RFA: Radio frequency ablation; IUFD: Intrauterine foetal demise; SIUGR: Selective intrauterine growth restriction; TITS: Twin-to-twin transfusion syndrome; TRAPs: Twin reversed arterial perfusion sequence; IUFD: Intrauterine foetal demise; PROM: Preterm rupture of membrane; TOP: Monochorionic tramniotic; GA: Gestational age; MCDA: Monochorionic diamniotic

\section{Acknowledgements}

We would like to thank our patients for cooperating with telephone-followup and allowing us to publish their final pregnancy outcome.

\section{Authors' contributions}

HM W drafted and revised the manuscript, and analysed and interpreted data for the work. Q Z wrote and contributed to the manuscript. XT W was responsible for conceiving the work and performing all the procedures. I $\mathrm{S}$ interviewed and assessed the children's development. PZ C, YY W and L L collected and analysed the data. HY L designed the work and was the sonographer for all the procedures; she also gave the final approval of the version to be published. All authors have read and approved the manuscript.

\section{Funding}

This research received the fund of the National Key Research and Development Programme of China (2018YFC1002900) from 2018, and the programme supported the cost of data collection and analysis.

\section{Availability of data and materials}

All data included in this study are available upon request by contact with the corresponding author. No administrative permission was required to access the raw data.

\section{Ethics approval and consent to participate}

This study was approved by the ethical committee of Shandong Provincial Hospital affiliated to Shandong First Medical University and written informed consent was signed by patients who agreed to participate.

\section{Consent for publication}

Not Applicable.

\section{Competing interests}

The authors declare that they have no competing interests.

\section{Author details}

'Department of Obstetrics, Shandong Provincial Hospital Affiliated to Shandong First Medical University, Jinan, Shandong, China. ${ }^{2}$ Department of Obstetrics, Maternal Child Health Care Hospital of Shandong Province, Jinan, Shandong, China. ${ }^{3}$ Key Laboratory of Birth Regulation and Control Technology of National Health Commission of China, Maternal Child Health Care Hospital of Shandong Province, Jinan, Shandong, China. ${ }^{4}$ Department of Neonatology, Shandong Provincial Hospital Affiliated to Shandong First Medical University, Jinan, Shandong, China.

Received: 14 July 2020 Accepted: 26 December 2020

Published online: 09 January 2021

\section{References}

1. Gratacos E. A systematic approach to the differential diagnosis and management of the complications of monochorionic twin pregnancies. Foetal Diagn Ther. 2012;32:145-55.

2. Lewi L, Deprest J, Hecher K. The vascular anastomoses in monochorionic twin pregnancies and their clinical consequences. Am J Obstet Gynecol. 2013:208:19-30

3. Quintero RA, Chmait RH, Murakoshi T, Pankrac Z, Swiatkowska M, Bornick PW, Allen MH. Surgical management of twin reversed arterial perfusion sequence. Am J Obstet Gynecol. 2006;194:982-91.

4. Deprest JA, Audibert F, Van Schoubroeck D, Hecher K, Mahieu-Caputo D. Bipolar coagulation of the umbilical cord in complicated monochorionic twin pregnancy. Am J Obstet Gynecol. 2000;182:340-5.

5. Paramasivam G, Wimalasundera R, Wiechec M, Zhang E, Saeed F, Kumar S. Radiofrequency ablation for selective reduction in complex monochorionic pregnancies. BJOG. 2010;117:1294-8.

6. Ville $Y$, Hyett JA, Vandenbussche FP. Endoscopic laser coagulation of umbilical cord vessels in twin reversed arterial perfusion sequence. Ultrasound Obstet Gynecol. 1994;4:396-8.

7. Lanna MM, Rustico MA, Dell'Avanzo M, Schena V, Faiola S, Consonni D, Righini A, Sxelsa B, Ferrazzi EM. Bipolar cord coagulation for selective feticide in complicated monochorionic twin pregnancies: 118 consecutive cases at a single center. Ultrasound Obstet Gynecol. 2012;39:407-13.

8. Kumar S, Paramasivam G, Zhang E, Jones B, Noori M, Prior T, Vasudeva A, Wimalasundera RC. Perinatal- and procedure-related outcomes following radiofrequency ablation in monochorionic pregnancy. Am J Obstet Gynecol. 2014;210:454 e451-6.

9. Tsao K, Feldstein VA, Albanese CT, Sandberg P, Lee H, Harrison MR, Farmer $\mathrm{DL}$. Selective reduction of acardiac twin by radiofrequency ablation. Am J Obstet Gynecol. 2002;187:635-40

10. Lee H, Wagner AJ, Sy E, Ball R, Feldstein VA, Goldstein RB. Efficacy of radiofrequency ablation for twin-reversed arterial perfusion sequence. Am J Obstet Gynecol. 2007;196:459 e451-4.

11. Meng X, Yuan P, Gong L, Wang X, Wu T, Wei Y, Zhao Y. Forty-five consecutive cases of complicated monochorionic multiple pregnancy treated with microwave ablation: A single-center experience. Prenat Diagn. 2019;39:293-8

12. Shaw CJ. Noninvasive high-intensity focused ultrasound treatment of twintwin transfusion syndrome_ A preliminary in vivo study. Sci Transl Med. 2016. Doi:https://doi.org/10.1126/scitranslmed.aaf2135.

13. Nobili E, Paramasivam G, Kumar S. Outcome following selective foetal reduction in monochorionic and dichorionic twin pregnancies discordant for structural, chromosomal and genetic disorders. Aust N Z J Obstet Gynaecol. 2013:53:114-18.

14. Abdel-Sattar M, Chon AH, Llanes A, Korst LM, Ouzounian JG, Chmait RH. Comparison of umbilical cord occlusion methods: Radiofrequency ablation versus laser photocoagulation. Prenat Diagn. 2018;38:110-6. 
15. Bebbington MW, Danzer E, Moldenhauer J, Khalek N, Johnson MP. Radiofrequency ablation vs bipolar umbilical cord coagulation in the management of complicated monochorionic pregnancies. Ultrasound Obstet Gynecol. 2012;40:319-24.

16. Lee H, Bebbington M, Crombleholme TM. North American foetal Therapy N. The North American foetal Therapy Network Registry data on outcomes of radiofrequency ablation for twin-reversed arterial perfusion sequence. Foetal Diagn Ther. 2013;33:224-9.

17. Sugibayashi R, Ozawa K, Sumie M, Wada S, Ito Y, Sago H. Forty cases of twin reversed arterial perfusion sequence treated with radio frequency ablation using the multistep coagulation method: a single-center experience. Prenat Diagn. 2016;36:437-43.

18. Wagata M, Murakoshi T, Ishii K, Muromoto J, Sasahara J, Murotsuki J. Radiofrequency Ablation with an Internally Cooled Electrode for Twin Reversed Arterial Perfusion Sequence. Foetal Diagn Ther. 2016;40:110-5.

19. Yinon Y, Ashwal E, Weisz B, Chayen B, Schiff E, Lipitz S. Selective reduction in complicated monochorionic twins: prediction of obstetric outcome and comparison of techniques. Ultrasound Obstet Gynecol. 2015;46:670-7.

20. Lewi L. Growth-discordance. Best Pract Res Clin Obstet Gynaecol. 2014;28: 295-303.

21. Rossi AC, D'Addario V. Umbilical cord occlusion for selective feticide in complicated monochorionic twins: a systematic review of literature. Am J Obstet Gynecol. 2009;200:123-9.

22. Slaghekke F, Lopriore E, Lewi L, Middeldorp JM, Van EW, Weingertner AS, Klumper FJ, DeKoninck P, Devlieger R, Kilby MD, Rustico MA, Deprest J, Favre R, Oepkes D. Fetoscopic laser coagulation of the vascular equator versus selective coagulation for twin-to-twin transfusion syndrome: an open-label randomised controlled trial. The Lancet. 2014;383:2144-51.

23. Di Mascio D, Khalil A, D'Amico A, Buca D, Panici PB, Flacco ME, Manzoli L, Liberati M, Nappi L, Berghella V, D'Antonio F. Outcome of twintwin transfusion syndrome according to Quintero stage of disease: systematic review and meta-analysis. Ultrasound Obstet Gynecol. 2020;56(6):811-20. https://doi.org/10.1002/uog.22054.

24. Diehl W, Diemert A, Grasso D, Sehner S, Wegscheider K, Hecher K. Fetoscopic laser coagulation in 1020 pregnancies with twin-twin transfusion syndrome demonstrates improvement in double-twin survival rate. Ultrasound Obstet Gynecol. 2017;50:728-35.

25. Sun L, Zou G, Yang Y, Zhou F, Tao D. Risk factors for foetal death after radiofrequency ablation for complicated monochorionic twin pregnancies. Prenat Diagn. 2018;38:499-503.

26. Peng R, Xie HN, Lin MF, Yang JB, Zhou Y, CHen HQ, Zhu YX. Clinical Outcomes after Selective foetal Reduction of Complicated Monochorionic Twins with Radiofrequency Ablation and Bipolar Cord Coagulation. Gynecol Obstet Invest. 2016;81:552-8.

27. Gratacos E, Lewi L, Munoz B, Acosta-Rojas R, Hernandez-Andrade E, Martinea JM, Carreras E, Deprest J. A classification system for selective intrauterine growth restriction in monochorionic pregnancies according to umbilical artery Doppler flow in the smaller twin. Ultrasound Obstet Gynecol. 2007:30:28-34.

28. Quintero RA, Morales WJ, Allen MH, Bornick PW, Johnson PK, Kruger Michael. Staging of twin-twin transfusion syndrome. J Perinatol. 1999;8: 550-5.

29. Ball RS. The Gesell Developmental Schedules: Arnold Gesell (1880-1961). J Abnorm Child Psychol. 1977;5:233-9.

30. van Klink JM, Koopman HM, Oepkes D, Walther FJ, Lopriore E. Long-term neurodevelopmental outcome in monochorionic twins after foetal therapy. Early Hum Dev. 2011;87:601-6.

31. van den Bos EM, van Klink JM, Middeldorp JM, Klumper FJ, Oepkes D, Lopriore E. Perinatal outcome after selective feticide in monochorionic twin pregnancies. Ultrasound Obstet Gynecol. 2013;41:653-8.

32. van Klink J, Koopman HM, Middeldorp JM, Klumper FJ, Rljken M, Oepkes D, Lopriore E. Long-term neurodevelopmental outcome after selective feticide in monochorionic pregnancies. BJOG. 2015;122:1517-24.

\section{Publisher's Note}

Springer Nature remains neutral with regard to jurisdictional claims in published maps and institutional affiliations.

Ready to submit your research? Choose BMC and benefit from:

- fast, convenient online submission

- thorough peer review by experienced researchers in your field

- rapid publication on acceptance

- support for research data, including large and complex data types

- gold Open Access which fosters wider collaboration and increased citations

- maximum visibility for your research: over $100 \mathrm{M}$ website views per year

At $\mathrm{BMC}$, research is always in progress.

Learn more biomedcentral.com/submissions 